STIs in Africa

\section{Sexually transmitted infections in Africa: single dose treatment is now affordable}

\section{J Pépin, D Mabey}

\section{There remains no financial obstacle to rapid and effective syndromic treatment of STls in developing countries}

$\mathrm{P}$ rompt treatment of sexually transmitted infections (STIs) with effective antibiotic regimens, preferably contained in a single, supervised dose, is a cornerstone of STI control. The World Health Organization (WHO) revised its treatment guidelines in 2001. ${ }^{1}$ A variety of regimens is proposed, from which national control programmes are encouraged to choose, depending on the susceptibility of local strains of Neisseria gonorrhoeae and Haemophilus ducreyi, and on the resources available to pay for treatment. WHO treatment guidelines reflect a tension between, on the one hand, the need to recommend the most effective single dose treatment and, on the other, the fact that this may not be available in many developing countries, especially in sub-Saharan Africa. Third generation cephalosporins, for example, have until recently been prohibitively expensive and, for that reason, are not included in the essential drugs list of some African countries. WHO guidelines have therefore included cheaper alternatives for the treatment of gonorrhoea, such as a 3 day course of co-trimoxazole, which are likely to be very much less efficacious. However, essential drug lists should respond to changing circumstances, and new drugs should be added when this is thought to be cost effective by groups of experts.

The price of many drugs has fallen dramatically in sub-Saharan Africa in recent years as a result of the development of a large generic drug industry in developing countries, such as India and China, and a vigorous campaign by WHO and NGOs, such as Médecins sans Frontières (MSF), for better accessibility to essential drugs.

Current prices and sources of a number of anti-infective drugs have been publicised in a recent update of a joint UN agencies-MSF document. ${ }^{2}$ Table 1 showns drug costs for regimens recommended by WHO, Centers for Disease Control and Prevention (CDC), and UK experts for the most common STIs. ${ }^{1{ }^{3}}$ When recommendations differed we selected the cheapest and/or most convenient. All treatments are to be given orally unless stated otherwise. Prices offered by a supplier may vary according to the quantities ordered, current competition, and other factors, so we conservatively used the median price (number of suppliers varies from two to 16). We also show prices offered by the International Dispensary Association (IDA), ${ }^{5}$ which includes additional drugs. To the latter must be added transportation costs and mark ups at various levels of the healthcare system.

For the treatment of gonorrhoea, there is no reason to recommend anything other than ciprofloxacin, to which no resistance has been reported so far from Africa, and which cures $99.8 \%$ of uncomplicated cases. $^{3}$ Ciprofloxacin resistance in $N$ gonorrhoeae emerged in Asia and more recently in parts of the United States and in England and Wales. ${ }^{6}$ This needs to be monitored in Africa through surveillance networks, but ciprofloxacin will probably remain very effective for at least a few years as the drug has been little used for indications other than gonorrhoea. Ceftriaxone (99\% efficacy) or its oral counterpart cefixime (97\%) could be used for pregnant women. ${ }^{13}$ There is no obvious reason why spectinomycin, kanamycin or, even worse, cotrimoxazole should continue to be recommended by WHO. ${ }^{1}$ A 2 g dose of azithromycin, also recommended by WHO, is more than 20 times more expensive than ciprofloxacin and probably less effective. For the treatment of Chlamydia trachomatis infection, doxycycline is so cheap that it should remain the first line treatment whereas azithromycin could be given to pregnant women. ${ }^{36}$ However, for sex workers, a core group having a crucial role in the dissemination of $C$ trachomatis and other sexually transmitted pathogens, azithromycin given under direct observation would guarantee compliance and lead to a $95-100 \%$ bacteriological eradication rate. $^{7}$ There are two reasons to prefer the ciprofloxacin/doxycycline combination for men with urethral discharge: doxycycline remains substantially cheaper than azithromycin, and there is a lack of data concerning the effectiveness of single dose azithromycin in the treatment of Mycoplasma genitalium-an emerging cause of urethritis in Africa. ${ }^{8}$

For women with vaginitis, repeated applications of messy vaginal creams can be forgotten. Topical azoles have a $80-90 \%$ efficacy similar to that of oral azoles for the treatment of candidiasis, both of which are superior to nystatin. ${ }^{4}{ }^{9}$ Generic clotrimazole as a vaginal pessary is available for single dose treatment, but even this convenient approach could be replaced with oral fluconazole, which is now cheaper. For the treatment of trichomoniasis, single dose metronidazole remains the standard drug, ${ }^{13}{ }^{4}$ with $88 \%$ efficacy, ${ }^{10}$ but single dose tinidazole, used for 30 years, is also recommended by WHO. ${ }^{1}$ Tinidazole is only marginally more expensive than metronidazole, better tolerated (less frequent nausea or vomiting), and cures $95 \%$ of cases. ${ }^{10}$ The only limiting step in overall single dose treatment of vaginitis remains the management of bacterial vaginosis, which causes up to $56-69 \%$ of cases of vaginal discharge in non-pregnant Africans. ${ }^{11}{ }^{12}$ Single dose metronidazole is a second choice, ${ }^{13}$ but its effectiveness is somewhat inferior to the $80-90 \%$ success obtained with a 7 day course of the same drug. ${ }^{13}$ Topical treatments with clindamycin cream or metronidazole gel require 3-7 days of application, are not available as generics, and are less efficacious than oral treatment. ${ }^{313}$ Single dose tinidazole offers potential advantages over metronidazole: fewer adverse effects and a longer half life (12-14 hours $v \quad 6-7$ hours). Contradictory results have been reported in trials of single dose tinidazole in bacterial vaginosis, which used different definitions of disease and of therapeutic success: cure rates of $51-71 \%,{ }^{14} 67-93 \%,{ }^{15} 92 \%,{ }^{16}$ and $97 \%{ }^{17}$ were described. Cure rates with single dose metronidazole among HIV infected women with bacterial vaginosis is only half of what is seen in their HIV negative counterparts, ${ }^{12}$ and this will need to be kept in mind when designing future trials.

In many parts of Africa, an increasing proportion of cases of genital ulcers are caused by herpes simplex, whereas chancroid is much less frequent than 20 years ago, perhaps to some extent because of higher rates of condom use during transactional sex and the widespread use of ciprofloxacin to treat gonorrhoea among core groups. There 


\begin{tabular}{|c|c|c|c|}
\hline \multirow[b]{2}{*}{ Infection } & \multirow[b]{2}{*}{ Treatment regimen } & \multicolumn{2}{|c|}{ Price for episode (US\$) } \\
\hline & & $\begin{array}{l}\text { Median price UN } \\
\text { agencies-MSF }\end{array}$ & IDA price \\
\hline \multirow[t]{4}{*}{ Gonorrhoea } & Ciprofloxacin 500 mg SD & 0.05 & 0.04 \\
\hline & Ceffriaxone $125 \mathrm{mg}$ IM SD & 0.50 & 0.48 \\
\hline & Cefixime $400 \mathrm{mg} \mathrm{SD}$ & 0.10 & NA \\
\hline & Spectinomycin $2 \mathrm{~g} I M \mathrm{SD}$ & 4.00 & NA \\
\hline \multirow[t]{3}{*}{ Chlamydia } & Doxycycline $100 \mathrm{mg} \mathrm{BID} \times 7 \mathrm{~d}$ & NA & 0.11 \\
\hline & Azithromycin $1 \mathrm{~g}$ SD & 0.60 & NA \\
\hline & Erythromycin $500 \mathrm{mg}$ QID $\times 7 \mathrm{~d}$ & 1.79 & 1.90 \\
\hline \multirow[t]{2}{*}{ Vaginal candidiasis } & Clotrimazole $500 \mathrm{mg}$ pessary SD & NA & 0.73 \\
\hline & Fluconazole 150 or $200 \mathrm{mg}$ SD & 0.20 & NA \\
\hline \multirow[t]{4}{*}{ Trichomoniasis } & Metronidazole 2 g SD & NA & 0.02 \\
\hline & Tinidazole 2 g SD & 0.05 & NA \\
\hline & Metronidazole $500 \mathrm{mg} \mathrm{BID} \times 7 \mathrm{~d}$ & NA & 0.08 \\
\hline & Tinidazole $500 \mathrm{mg} \mathrm{BID} \times 7 \mathrm{~d}$ & 0.17 & NA \\
\hline \multirow[t]{3}{*}{ Bacterial vaginosis } & Metronidazole $500 \mathrm{mg} \mathrm{BID} \times 7 \mathrm{~d}$ & NA & 0.08 \\
\hline & Metronidazole 2 g SD & NA & 0.02 \\
\hline & Tinidazole 2 g SD & 0.05 & NA \\
\hline \multirow[t]{5}{*}{ Chancroid } & Ciprofloxacin 500 mg SD & 0.05 & 0.04 \\
\hline & Ciprofloxacin $500 \mathrm{mg}$ BID $\times 3 \mathrm{~d}$ & 0.32 & 0.23 \\
\hline & Erythromycin $500 \mathrm{mg}$ TID $\times 7 \mathrm{~d}$ & 1.34 & 1.43 \\
\hline & Azithromycin $1 \mathrm{~g}$ PO SD & 0.60 & NA \\
\hline & Ceffriaxone $250 \mathrm{mg}$ IM SD & 1.00 & 0.95 \\
\hline Syphilis & Benzathine penicillin 2.4 IM SD & NA & 0.23 \\
\hline Herpes, primary & Aciclovir $400 \mathrm{mg}$ TID $\times 7 \mathrm{~d}$ & 1.45 & 2.10 \\
\hline Herpes, recurrent & Aciclovir $400 \mathrm{mg}$ TID $\times 5 \mathrm{~d}$ & 1.04 & 1.50 \\
\hline
\end{tabular}

is an obvious need for country specific data about the aetiology of genital ulcers, and at some point it may become irrational to treat all such cases for syphilis and chancroid as currently recommended. ${ }^{1}$ A single injection of benzathine penicillin remains the gold standard treatment of syphilis. ${ }^{134}$ There is no convincing evidence that HIV infected patients with primary syphilis should be treated more aggressively than the seronegatives ${ }^{13}$ or that a longer treatment should be given to pregnant women, ${ }^{18}$ and sound public health policies are generally the most simple. For chancroid, single dose ciprofloxacin, although not recommended by WHO, seems a reasonable option; it is considerably cheaper than single dose azithromycin or ceftriaxone, and seems to be effective even in HIV infected patients, ${ }^{19}$ in contrast to ceftriaxone, which should be kept for pregnant women. As long as the current price structure persists, there is little reason to prescribe macrolides. The price of aciclovir has dropped considerably in recent years, but a 5 day course remains relatively expensive for a drug that, in self limited recurrent herpes, will only modestly shorten duration of lesions. Aciclovir should be reserved for the treatment of genital herpes in known HIV seropositives (whose herpetic ulcers can be severe or prolonged) or in core groups with high HIV prevalence, such as sex workers.

There remains no financial obstacle to rapid and effective syndromic treatment of STI in developing countries, to a large extent because the interests of the public health sector coincided with those of the profit oriented generic drug industry and market forces were not hampered by protectionist regulations. We hope that current negotiations under the aegis of the World Trade Organization will not prevent further progress being made towards providing affordable solutions to health priorities identified by WHO. Certainly the right hand must be aware of what the left hand is doing.

\section{CONTRIBUTORS}

Both authors have contributed equally to the writing up of this text.

Sex Transm Infect 2003;79:432-434

n............................

Authors' affiliations

J Pépin, Department of Microbiology and Infectious Diseases, University of Sherbrooke, Canada

D Mabey, Department of Infectious and Tropical Diseases, London School of Hygiene and Tropical Medicine, London, UK

Conflict of interest: None.

Correspondence to: Professor Jacques Pépin, Department of Microbiology and Infectious Diseases, University of Sherbrooke, Quebec, Canada J1H 5N4;

Jacques.pepin@usherbrooke.ca

\section{REFERENCES}

1 World Health Organization. Guidelines for the management of sexually transmitted infections.
Geneva, 2001 (www.who.int/hiv/ hiv_aids_2001_01.pdf).

2 UNICEF-UNAIDS-WHO-MSF. Sources and prices of selected medicines and diagnostics for people living with HIV/AIDS. Geneva, 2003 (www.who.int/medicines/organization/par/ ipc/sources-prices.pdf).

3 Centers for Disease Control and Prevention. Sexually transmitted diseases treatment guidelines 2002. Morb Mortal Wkly Rep 2002;51(RR6): 1-82 (www.cdc.gov/std/treatment/ rr5106.pdf)

4 Clinical Effectiveness Group. UK national guidelines on sexually transmitted infections and closely related conditions. Sex Trans Infect 1999;75(Suppl 1):S1-S88.

5 International Dispensary Association. IDA electronic order forms (December 2002) (www.ida.nl/engels/ida.htm?9)

6 Fenton KA, Ison C, Johnson AP, et al. Ciprofloxacin resistance in Neisseria gonorrhoeae in England and Wales in 2002 Lancet 2003:361:1867-9.

7 Adimora AA. Treatment of uncomplicated genital Chlamydia trachomatis infections in adults. Clin Infect Dis 2002;35(Suppl 2):S183-6.

8 Pépin J, Sobela F, Deslandes S, et al. Aetiology of urethral discharge in West Africa: the role of Mycoplasma genitalium and Trichomonas vaginalis. Bull World Health Organ 2001:79:118-26.

9 Watson MC, Grimshaw JM, Bond CM, et al. Oral versus intravaginal imidazole and triazole antifungal treatment of uncomplicated vulvovaginal candidiasis (thrush). Cochrane Database Systematic Reviews. Latest version, 28 May 2001.

10 Forna F, Gulmezoglu AM. Interventions for treating trichomoniasis in women. Cochrane Database Systematic Reviews. Latest version, 29 May 2000.

11 Behets FMT, Andriamiadana J, Randrianasolo D, et al. Laoratory diagnosis of sexually transmitted infections in women with genital discharge in Madagascar: implications for primary care. Int J STD AIDS 2002;13:606-11.

12 Moodley P, Wilkiinson D, Connolly C, et al. Influence of HIV-1 coinfection on effective management of abnormal vaginal discharge. Sex Transm Dis 2003:30:1-5.

13 Koumans EH, Markowitz LE, Hogan V, for the CDC BV Working Group. Indications for therapy 
and treatment recommendations for bacterial vaginosis in nonpregnant and pregnant women: a synthesis of data. Clin Infect Dis 2002;35(Suppl 2):S152-72.

14 Schindler EM, Thamm H, Ansmann EB, et al. Treatment of bacterial vaginitis. Multicenter, randomized, open study with tinidazole in comparison with metronidazole. Fortschr Med 1991; 109: 138-40.

15 Ekgren J, Norling BK, Degre $M$, et al. Comparison of tinidazole given as a single dose and on 2 consecutive days for the treatment of non-specific bacterial vaginosis. Gynecol Obstet Invest 1988;26:313-17.

16 Mohanty KC, Deighton R. Comparison of $2 \mathrm{~g}$ single dose of metronidazole, nimorazole and tinidazole in the treatment of vaginitis associated with Gardnerella vaginalis. Antimicrob Agents Chemother 1987; 19:393-9.

17 Vutyavanich T, Pongsuthirak P, Vannareumol P, et al. A randomised double-blind trial of tinidazole treatment of the sexual partners of females with bacterial vaginosis. Obstet Gynecol 1993:82:550-4.
18 Watson-Jones D, Gumodoka B, Changalucha J et al. Syphilis in pregnancy in Tanzania II. The effectiveness of antenatal syphilis screening and single dose benzathine penicillin treatment for the prevention of adverse pregnancy outcomes. $J$ Infect Dis 2002;186:948-57.

19 Malonza I, Tyndall M, Ndinya-Achola JO et al. A randomized, double-blind, placebocontrolled trial of single-dose ciprofloxacin versus erythromycin for the treatment of versus erythromycin for the treatment of
chancroid in Nairobi, Kenya. J Infect Dis 1999:180:1886-93.

\section{CHESTER CHRONICLES}

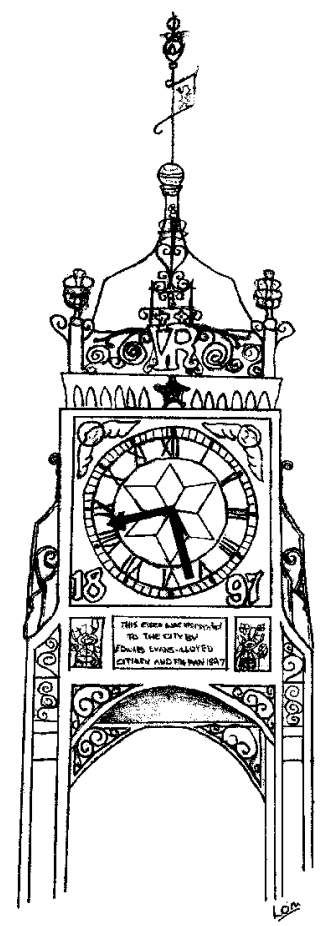

EASTGATE CLOCK, CHESTER

\section{Cabin fever}

thought I'd seen it all before, but this just takes the biscuit. This is the worst clinic premises I have ever seen. It appears to be a green Portacabin in the middle of a car park. When I tentatively opened the door, directly into the $6 \mathrm{ft}$ by $6 \mathrm{ft}$ waiting room, a gust of rain and wind whipped through the flimsy building. Eurocamp has bigger mobile homes than this building, meant to cater for a catchment population of almost $1 / 4$ million.

My heart went out to the hard working, sympathetic staff, who actually use this place, and I can only admire the dedication and fortitude that gives them the courage to actually come in every day and cope with the indignity of working in such an inadequate structure.

Strange, isn't it, how Portacabins seem to be considered good enough for managing patients with sexually transmitted infections (STIs)? Can you imagine a newly appointed cardiologist, orthopaedic surgeon, or a consultant in any of the glamorous specialties being shown around their new outpatient department, which consisted of a thrown together temporary structure in the middle of a completely jam packed hospital car park? It's all part of the old attitude that the acquisition of STIs is self inflicted and patients with such problems should be grateful that they are seen anywhere, so therefore anything will do. The extraordinary thing is that many of our own patients who actually have an STI share this attitude themselves, so they feel worthless, guilty and ashamed, and appear to be glad to be seen anywhere, even if it is a dilapidated Portacabin. This attitude is reflected in the incredible difficulty involved in getting any of our patients to complain about anything! It therefore falls to us as consultants in the specialty to do the complaining for them, and inevitably we get tarnished with the brush of whinging consultants only interested in empire building, the golf course, and private practice. Well, if that's the case, we have been singularly unsuccessful at all three. The numbers of Portacabins dotted around the country are a testimony to our failed attempts to get buildings that help reduce the distress, embarrassment, and indignity that many of our patients feel. As for the golf course, there have been several failed attempts to get a GUM golf society established over the past 15 years by the few stalwarts who actually possess a set of clubs. I went to one "day out" once, and if it hadn't been for the friendly microbiologists and other hangers-on that turned up, the day could not have happened at all. As for private practice-now there's a laugh. Let's be honest here and admit that in every specialty it's waiting lists that generate private practice. Yet, here we are, the only specialty in medicine striving King Canute-like for open access clinics.

Now I had tried to park in the car park near that clinic, but couldn't find a space and ended up accidentally in the car park of the annexed private wing of the same trust. I therefore went through the private section and the striking contrast only induced melancholy and despair. The difference between the two environments could not have been more stark. All it takes to create a decent environment is a proper building, a bit of imaginative lighting, carpets, and furniture that haven't come from some clearout or old people's home.

Individuals who have been unlucky enough to acquire an STI or even the worry of one should not have their shame and embarrassment compounded by a health service that considers a Portacabin to be a modern outpatient department. Well, it isn't!

C O'Mahony

Department of Genitourinary Medicine, Countess of Chester Hospital, Chester CH2 IUL, UK; colm.omahony@coch.nhs.uk 